\title{
Co-administration of vitamin D3 and Lacticaseibacillus paracasei DG increase 25-hydroxyvitamin D serum levels in mice
}

Ignazio Castagliuolo', Melania Scarpa', Paola Brun', Giulia Bernabe', Valeria Sagheddu², Marina Elli², Walter Fiore ${ }^{3}$, Valerio De Vitis ${ }^{3}$ and Simone Guglielmetti ${ }^{4^{*}}$ (D)

\begin{abstract}
Purpose: Subclinical vitamin D (vitD) deficiency enhances the predisposition to a myriad of acute and chronic pathologies in many people worldwide. Due to the scarcity of vitD-rich foods, the consumption of supplements or fortified foods can be required to maintain healthy serum levels of 25 -hydroxyvitamin $\mathrm{D}[25(\mathrm{OH}) \mathrm{D}]$, and the major circulating form of vitD that is commonly measured in serum to determine the vitD status. Since the vitD absorption seems to resemble that of lipids, improved emulsification in the gut could favor vitD permeation through the enterocyte membrane. Contextually, we hypothesized that a microorganism with cholecalciferol (vitD3)-solubilization properties may potentially result in enhanced serum vitD levels.

Methods and results: Six probiotic strains were screened for their ability to create a stable suspension of vitD 3 in water: Lacticaseibacillus paracasei DG, L. paracasei LPC-S01, L. paracasei Shirota, L. rhamnosus GG, Limosilactobacillus reuteri DSM 17938, and Lactobacillus acidophilus LA5. The DG strain displayed the strongest vitD3 solubilization ability and, consequently, were used in an in vivo trial where a commercial preparation of vitD3 in refined olive oil was administered by gavage to CD-1 mice with or without the concurrent administration of L. paracasei DG. ELISA measurements showed that the DG strain significantly increased the serum levels of $25(\mathrm{OH})$ D when administered once a day for 1 week in association with the vitD3 supplement.
\end{abstract}

Conclusion: This preliminary pre-clinical study suggests that the combined administration of L. paracasei DG with an oil-based cholecalciferol supplement could contribute to the maintenance of the adequate $25(\mathrm{OH}) \mathrm{D}$ serum levels in people at risk of vitD deficiency.

Keywords: Probiotics, Vitamin D, Cholecalciferol supplementation, Bioavailability, Biosurfactant

\section{Background}

Vitamin D is the generic name for a group of liposoluble pro-hormones consisting of five different forms of secosteroids named D1, D2, D3, D4, and D5. In humans, the most important forms are vitamin D2 (also known

\footnotetext{
*Correspondence: simone.guglielmetti@unimi.it

${ }^{4}$ Division of Food Microbiology and Bioprocesses, Department of Food, Environmental and Nutritional Sciences (DeFENS), University of Milan, 20133 Milan, Italy

Full list of author information is available at the end of the article
}

as ergocalciferol), which has vegetal origin, and vitamin D3 (cholecalciferol), which derives from animal food or is synthesized in the skin upon sun exposure. Vitamins D2 and D3 are in a biologically inactive form and must undergo two hydroxylation reactions, the first in the liver and the second in the kidneys, to be converted in the bioactive forms. Specifically, in the liver, vitamins D2 and D3 are converted into 25-hydroxycholecalciferol (calcifediol) and 25-hydroxyergocalciferol. Calcifediol and 25-hydroxyergocalciferol are indicated together as 25-hydroxyvitamin $\mathrm{D}(25(\mathrm{OH}) \mathrm{D})$, which is the major circulating form 
of vitamin $\mathrm{D}$ and is commonly measured in serum to determine human vitamin D status (Hollis 1996). Finally, the bioactive form of vitamin D is produced in the kidneys, where calcifediol is further hydroxylated into calcitriol (1,25-dihydroxycholecalciferol; 1,25(OH)2D3), and 25-hydroxyergocalciferol into 1,25-dihydroxyergocalciferol (1,25(OH)2D2) (Holick et al. 1971, Norman et al. 1971).

Vitamin D has been demonstrated to be essential for multiple biological processes including bone-mineral homeostasis, regulation of innate and adaptive immune function, cellular proliferation and differentiation, and apoptosis (Umar et al. 2018). Accordingly, numerous studies demonstrated a relationship between vitamin D deficiency and increased risk of a myriad of acute and chronic pathologies such as cardiovascular disease, cancer, autoimmune diseases, infectious diseases, and neurological conditions (Holick 2017, Yang et al. 2013, Zisi et al. 2019).

It was estimated that vitamin D deficiency/insufficiency affects about one billion people, being one of the most underdiagnosed and undertreated medical condition worldwide (Holick 2007, Holick 2017). Numerous population groups are at increased risk of vitamin D deficiency and insufficiency, including pregnant women, people with increased skin melanin pigmentation, obese children and adults, and persons with abstinence from direct sun exposure (Holick 2017). In addition, vitamin D deficiency can also be determined by therapies such as those directed to the reduction of blood cholesterol levels, which can reduce the absorption of sterols and, therefore, also the absorption of fat-soluble vitamins, including vitamin D (Nasirpour et al. 2019). Considering the scarcity of foods rich in vitamin $\mathrm{D}$, the integration of diet with reinforced foods and supplements of vitamins D2 and D3 is attracting increasing attention as an effective strategy for several health-promoting purposes including the prevention of fractures in elderly women (Bergman et al. 2010), the reduction of gestational diabetes, low birth weight, and preeclampsia in pregnancy (Palacios et al. 2019); the anti-inflammatory activity in the lungs of mechanically ventilated patients (Leclair et al. 2019); the improvement of lipid profiles in subjects with hypercholesterolemia (Dibaba 2019) and chronic kidney disease (Milajerdi et al. 2019); and the reduction of atopic dermatitis severity (Hattangdi-Haridas et al. 2019). Notably, it was also suggested that vitamin D supplementation can significantly contribute to the prevention and treatment of the COVID-19 (Boulkrane et al. 2020, Cutolo et al. 2020, Grant et al. 2020).

The proportion of ingested vitamin D amount that ultimately reaches the systemic circulation can vary abundantly, depending on a plethora of factors such as the molecular form of the ingested vitamin, the matrix of co-ingested food (e.g., the amount and type of fatty acids and the presence of dietary fibers), the interaction with other fat soluble compounds, the bile secretions, the intestinal wall integrity, the gastro-intestinal luminal $\mathrm{pH}$, and host-associated factors (e.g., age, inflammatory state, obesity). Most of these factors influence the possibility that the non-polar lipid molecules of vitamin $\mathrm{D}$ can get accessed to enterocytes and get absorbed (Maurya and Aggarwal 2017). It is generally assumed that vitamin D absorption follows the same steps described for major lipids such as triacylglycerols, cholesterol, and phospholipids, i.e., emulsification and solubilization in mixed micelles, diffusion in the watery luminal environment, and permeation through the enterocyte membrane (Borel et al. 2015; Tso and Fujimoto 1991). This passive diffusion process through mixed micelles is probably not the exclusive mechanism of absorption but appears to be the dominant mechanism for the non-hydroxylated species of vitamin D (i.e., vitamin D2 and vitamin D3) at pharmacological concentrations (Borel et al. 2015, Maurya and Aggarwal 2017). In light of the proposed mechanism of vitamin D absorption, most commercial vitamin D supplements are constituted by fat-soluble preparations. In addition, supplements including vitamin D3 nanoemulsion formulations, which have been demonstrated to enhance cholecalciferol bioavailability, have been marketed (Marwaha and Dabas 2019). Interestingly, it was also reported a significant increase of serum $25(\mathrm{OH}) \mathrm{D}$ in hypercholesterolemic adults in response to the oral administration of the probiotic bacterial strain Limosilactobacillus reuteri (formerly Lactobacillus reuteri) NCIMB 30242 (Jones et al. 2013). Notably, vitamin D was the only fat-soluble vitamin affected by the probiotic intake, whereas the levels of vitamins A, E, and beta-carotenes did not change (Jones et al. 2013). Since it was reported that dietary vitamin $\mathrm{D}$ absorption could be enhanced at higher hydrogen ion concentrations (Hollander et al. 1978), the authors hypothesized that the observed increased serum levels of vitamin D could be a consequence of the acidification of the small bowel lumen resulting from the metabolism of L. reuteri. Despite the promising results, to the best of our knowledge, no other studies investigated the potential ability of probiotic microorganisms to improve vitamin D absorption and bioavailability. For this reason, in the present study, we aimed to test in vivo in a murine model the ability of a probiotic bacterial strain to increase the serum levels of vitamin $\mathrm{D}$, when the bacterial cells were administered together with a commercial preparation of vitamin D3 in olive oil. We show that the probiotic bacterial strain used in the study, which 
was selected based on its increased ability to solubilize cholecalciferol compared to other Lactobacillaceae probiotics, can significantly increase the serum levels of $25(\mathrm{OH}) \mathrm{D}$ in mice following administration once a day for 1 week in association with the commercial vitamin D3 supplement.

\section{Results \\ Lacticaseibacillus paracasei DG cells efficiently emulsify cholecalciferol in water}

Six lactic acid bacterial strains were tested for their potential ability to create a stable suspension of vitamin D in water: L. paracasei DG, L. paracasei LPCS01, L. paracasei Shirota, L. rhamnosus GG, L. reuteri DSM 17938, and L. acidophilus LA5. To this aim, PBSwashed bacterial cells in PBS were mixed with a solution of vitamin D3 in refined olive oil $(10: 1 \mathrm{v} / \mathrm{v})$. Then, an aliquot of the phase below the oil was analyzed by HPLC to quantify the solubilization of cholecalciferol in the aqueous fraction. The obtained results revealed a significant increase of cholecalciferol in the aqueous phase only for strains L. paracasei DG and L. rhamnosus GG (Fig. 1). In particular, the cells of $L$. paracasei DG displayed the strongest ability over the other strains tested. Interesting, this ability resulted to be strain-specific, since the vitamin D3 solubilization ability of the other two strains of the same species, i.e., $L$. paracasei, LPC-S01, and Shirota, resulted negligible (Fig. 1). According to the results of this experiment, $L$. paracasei DG was selected for the in vivo vitamin D bioavailability experiment in mouse model.

\section{Dietary vitamin D increases serum 25(OH) D when co-administered with probiotic bacterial cells}

In order to assess the ability of the probiotic bacterium L. paracasei DG to enhance vitamin D bioavailability, a commercial preparation of cholecalciferol in refined olive oil (DIBASE) was administered to mice by gavage with or without the concurrent administration of $L$. paracasei DG cells, according to the study design described in Fig. 2. Then, the concentration of $25(\mathrm{OH}) \mathrm{D}$ was measured by ELISA in mouse serum collected $3 \mathrm{~h}$ after the last gavage.

In control CD-1 mice on regular chow diet (mouse group I), $25(\mathrm{OH})$ D serum levels ranged between 36 and $71 \mathrm{ng} / \mathrm{ml}$ (mean \pm standard deviation $58 \pm 13 \mathrm{ng} /$ ml; Fig. 3). A single-dose (group II) or daily 1 week (D1W; group III) administration of vitamin D3 had no significant effect on serum $25(\mathrm{OH}) \mathrm{D}$ compared to the control (Fig. 3). Similarly, daily administration of the probiotic L. paracasei DG for a week, alone or in combination with a single dose of vitamin D3, did not affect significantly $25(\mathrm{OH}) \mathrm{D}$ serum levels compared to control mice (Fig. 3). Nonetheless, serum 25(OH) D level was slightly but significantly higher after the single-dose supplementation of vitamin D3 (group II; $67 \pm 4 \mathrm{ng} / \mathrm{ml}$ ) compared to D1W vitamin D3 (group III; $54 \pm 6 \mathrm{ng} / \mathrm{ml}$ ) and single-dose vitamin D3 + DG cells (group V; $57 \pm$ $6 \mathrm{ng} / \mathrm{ml}$ ) administrations (Fig. 3). Collectively, the serum levels of 25-hydroxyvitamin D for mice in groups I to $\mathrm{V}$

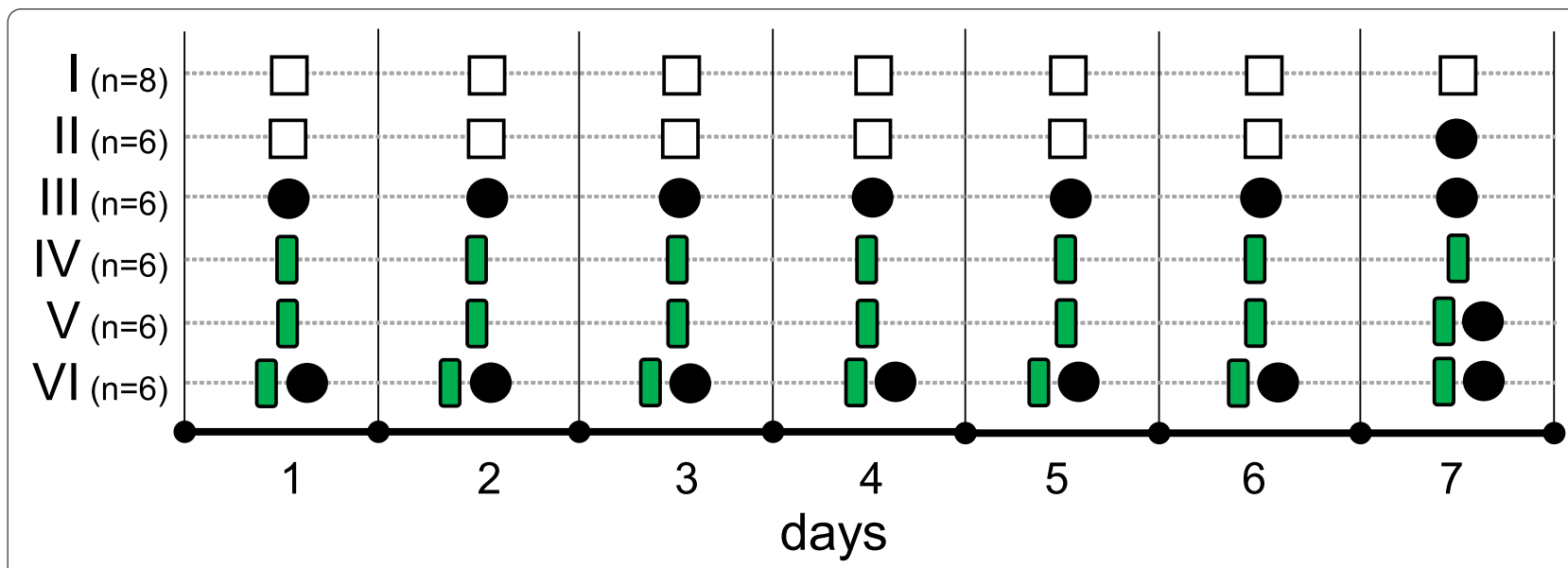

vehicle

Fig. 1 Cholecalciferol-emulsificationproperties of Lactobacillaceae probiotic strains. Statistically significantdifferences were determined through unpaired t test with Welch's correction ( $n=3$ ) performed after the Levene's test,which evidenced that the variance between groups was different (Levene's $P=0.005)$. ${ }^{* *} P<0.01 ;{ }^{*} P<0.05$ 


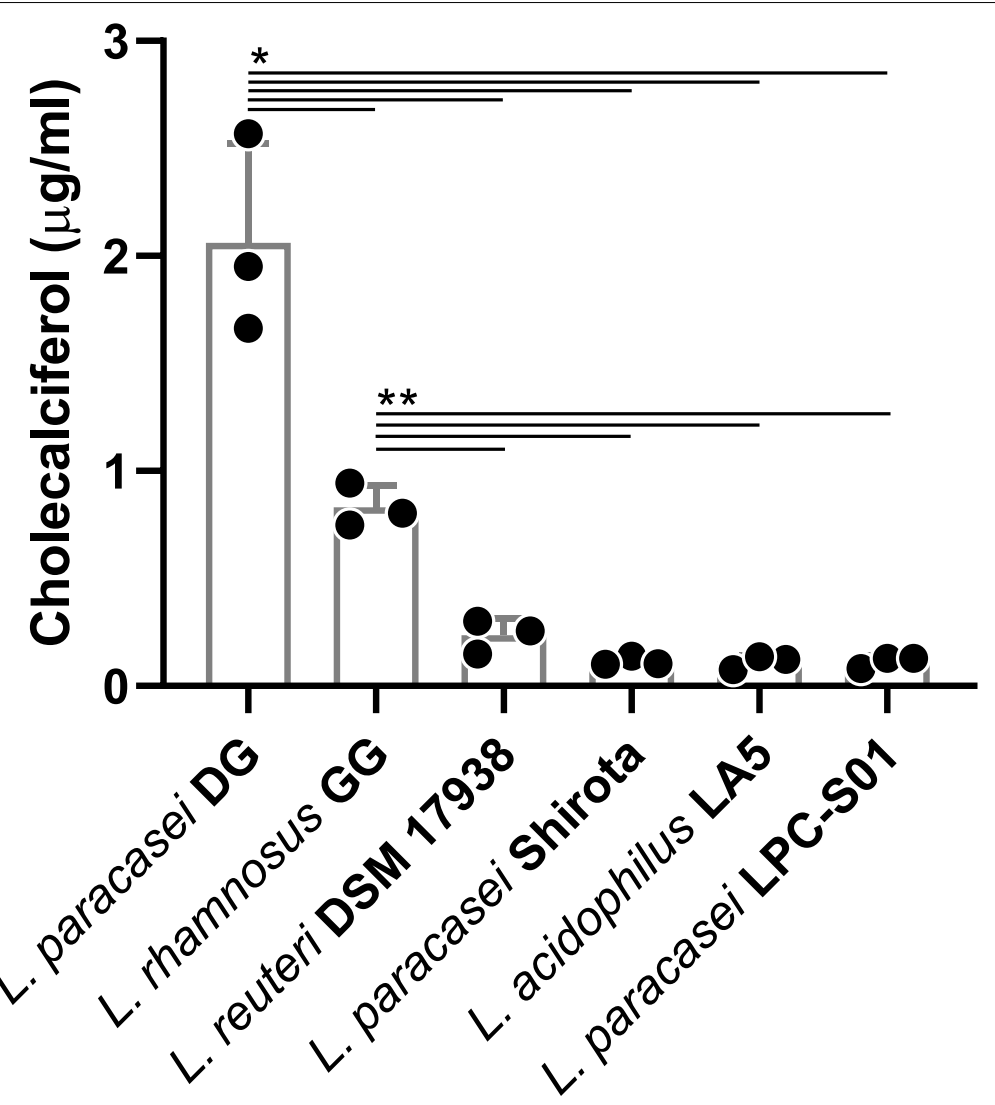

Fig. 2 Designof the trial in mouse model. Vehicle, vitamin D3, and L. paracasei DG cells were administered to mice by gavage. Vehicleconsisted of an aqueous solution of sucrose $20 \%$ + glycerol $10 \%$ (w/vol).Bacterial cells were suspended in the same vehicle. *500 IU of vitamin D3 inrefined olive oil (DIBASE) were administered per single gavage. ${ }^{* *} 10^{8} \mathrm{CFU}$ s of L. paracasei DG wereadministered per single gavage

were all between 35 and $74 \mathrm{ng} / \mathrm{ml}(58 \pm 10 \mathrm{ng} / \mathrm{ml})$. On the contrary, when $10^{8}$ CFUs of L. paracasei DG were administered in combination with the vitamin D3 supplement once a day for 1 week, the serum concentration of $25(\mathrm{OH}) \mathrm{D}$ ranged between 84 and $89 \mathrm{ng} / \mathrm{ml}$ (group $\mathrm{VI} ; 88 \pm 2 \mathrm{ng} / \mathrm{ml}$ ) (Fig. 3), corresponding on average to 50,62 , and $55 \%$ increase compared to control (group I), 1-week administration of vitamin D3 (group III) and the sole administration of DG cells (group IV), respectively. Notably, the significant increase of $25(\mathrm{OH}) \mathrm{D}$ serum levels was observed only when $L$. paracasei DG cells were administered together with vit. D3 for 1 week and not when the vitamin was administered as a single dose at day 7 .

\section{Discussion}

Severe vitamin D deficiency is very rare in developed countries. Nonetheless, increasing evidence is demonstrating that subclinical vitamin $\mathrm{D}$ deficiency affects a large number of people worldwide, resulting in an enhanced predisposition to several medical conditions ranging from frailty (Halfon et al. 2015) to neurological diseases (Dobson et al. 2018). For this reason, in recent years, several experts advised that consumption of supplements or fortified foods is required to meet the daily need of vitamin D (Papadimitriou 2017; Smith et al. 2017; Wimalawansa 2012). However, the precise extent of supplementation needed is difficult to be defined, due to intrinsic differences in the requirement of any specific population group and also because of the wide inter-subject variability in vitamin D absorption efficiency (Borel et al. 2015).

Although with an efficiency lower than that of triacylglycerols, it is generally assumed that the absorption of vitamin $D$ resembles that of lipids in the human small bowel (Borel et al. 2015). Therefore, it appears plausible that improved emulsification of vitamin $\mathrm{D}$ in the gut may favor its diffusion across the watery environment of lumen, enhancing the contact with the apical side of the enterocytes, and, therefore, permitting its permeation through the enterocyte membrane.

Several species of the Lactobacillaceae family have been demonstrated to produce biosurfactants (Satpute et al. 2016), i.e., amphiphilic molecules of different chemical 


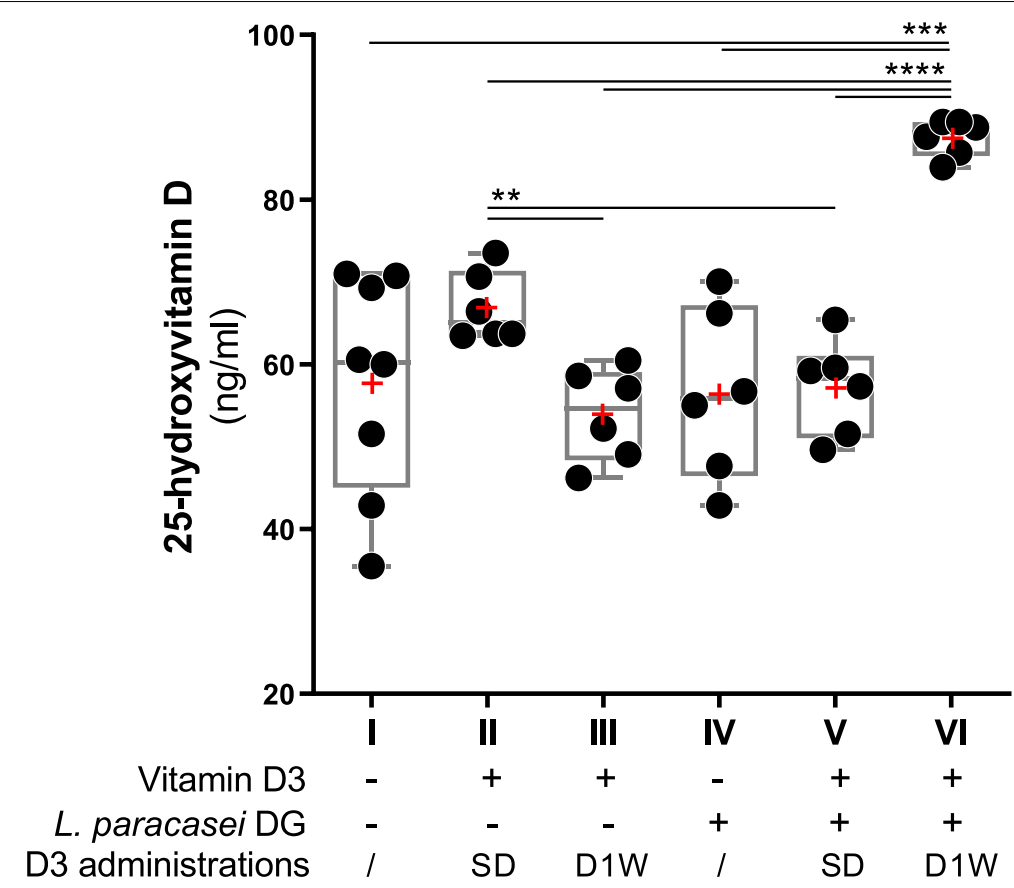

Fig. 3 Levelsof 25-hydroxyvitamin D [25(OH)D] in mouse serum samples collected $3 \mathrm{~h}$ after thelast gavage, as determined through ELISA measurements. Red symbols (+) indicatethe mean. Lacticaseibacillus paracaseiDG cells were administered to mice by gavage once a day for 1 week. Samplegroups (from I to VI) are according to Fig. 2. - not administered; +administered. SD, single-dose administration of vitamin D3; D1W, daily administration of vitamin D3 for 1 week. Statistically significant differences were determinedthrough unpaired t test with Welch's correction ( $n=3$ ) performed after the Levene's test, which evidenced that thevariance between groups was different (Levene's $P=0.021)$. ${ }^{* * * *} P<0.0001$; ${ }^{* * *} P<0.001$; ${ }^{*} P<0.01$

nature (e.g., glycolipids, phospholipids, lipopeptides, and other polymers) that may have deterging, emulsifying, foaming, or dispersing activity (Jahan et al. 2020; Santos et al. 2016). Therefore, it can be hypothesized that biosurfactant-producing microorganisms, once in the gut, may contribute to the emulsification of vitamin $\mathrm{D}$, favoring its contact with the epithelium and, consequently, its absorption. Interestingly, biosurfactant production has been also reported for microorganisms that are commonly used as probiotics such as L. casei/paracasei, L. rhamnosus, and L. acidophilus (Morovic et al. 2016). Contextually, in this study, we selected six Lactobacillaceae strains with well-documented probiotic properties to test in vitro their ability to solubilize cholecalciferol in water. Specifically, we included in the analysis Lacticaseibacillus paracasei Shirota, which is considered the first probiotic ever (Nanno et al. 2011), Lacticaseibacillus rhamnosus GG, the most studied probiotic bacterium (Capurso 2019), and Lacticaseibacillus paracasei DG, one of the most commonly consumed probiotics in Italy (Arioli et al. 2018; Cremon et al. 2018). In addition, we also studied three other probiotic strains with documented properties that can be commonly found in probiotic foods and supplements marketed in Europe, i.e., Lactobacillus acidophilus LA5 (Bogovic Matijasic et al. 2016; Zarrati et al. 2013), Lacticaseibacillus paracasei LPC-S01 (Balzaretti et al. 2015; Koirala et al. 2020), and Limosilactobacillus reuteri DSM 17938 (Mobini et al. 2017; Patro-Golab and Szajewska 2019). The experiment we carried out revealed a wide difference among tested bacteria, which displayed vitamin D3-emulsification ability in a strain-specific fashion. Interestingly, only one out of the three L. paracasei tested, viz. strain DG, significantly increased the amount of cholecalciferol in the aqueous phase. The emulsifying capacity of $L$. paracase $i$ DG was also significantly higher than that of $L$. rhamnosus GG, which was previously demonstrated to produce biosurfactant molecules (Ciandrini et al. 2016). The molecular determinant of the emulsifying ability of strain DG is not known, but we can speculate that a significant contribution can be provided by the unique rhamnoserich hetero-exopolysaccharide (EPS) that L. paracasei DG accumulates on the outer cell surface (Balzaretti et al. 2017). Reportedly, bacterial EPS macromolecules may exert efficient emulsifying properties toward different hydrophobic molecules such as crude oils and hydrocarbons (Calvo et al. 2002; Gutierrez et al. 2009; Gutierrez et al. 2013). 
Due to the peculiar ability of DG cells to facilitate the solubilization of cholecalciferol in an aqueous environment, this strain was administered to mice in association with the vitamin D3 supplement used in the in vitro solubilization assay, in order to assess the potential increase of vitamin bioavailability.

The serum levels of 25-hydroxyvitamin D in CD-1 male mice were not significantly affected by the administration of vitamin D3 alone, either in a single dose or daily for 1 week. Similarly, we did not observe a significant change of $25(\mathrm{OH}) \mathrm{D}$ levels when the probiotic bacterium was gavaged daily for 1 week, either alone or together with a single dose of vitamin D3 administered the last day of the trial. For all these five groups of mice, in fact, the levels of 25 -hydroxyvitamin $\mathrm{D}$ were in a range that is in line with the literature concerning the normal vitamin D levels of mice under regular chow diet (Ghaly et al. 2018, Mallya et al. 2016). Nonetheless, notably, when the vitamin D3 supplement and the probiotic bacterial cells were mixed and administered for 7 consecutive days, we observed a sharp enhancement of serum 25-hydroxyvitamin D levels in all mice, suggesting the potential ability of the bacterial cells to enhance the bioavailability, in accordance with our initial hypothesis. However, the mechanism supporting the increase in $25(\mathrm{OH}) \mathrm{D}$ levels following the coadministration of vitamin D with strain DG is not known, and additional experiments are needed to confirm that the cholecalciferol solubilization properties of DG cells may be relevant. Other possible mechanisms can be hypothesized, such as the acidification of the luminal $\mathrm{pH}$ due to lactic acid production, as previously proposed (Jones et al. 2013). In addition, we can speculate that gavaged bacterial cells may stimulate the secretion of bile and pancreatic juices, which could result into more efficient micelle formation and, consequently, enhanced cholecalciferol absorption. In support of this speculation, a recent publication showed that $L$. paracasei DG administration increased the amino acid absorption from plant proteins in physically active men (Jager et al. 2020).

Vitamin D was shown to exert important roles in the gut, where it is involved in the modulation of both mucosal immunity and normal growth of epithelial cells (Cross et al. 2011). In addition, vitamin D status was associated with the composition and function of the intestinal microbiota (Weiss and Litonjua 2015). Therefore, the spectrum of actions of vitamin $\mathrm{D}$ in the gut resembles the activities that have been commonly reported for probiotic microorganisms (Shang and Sun 2017), and for this reason, the co-administration of probiotics and vitamin $\mathrm{D}$ was supposed to synergistically promote beneficial effects for the human intestinal health (Shang and Sun 2017). In this context, the combination of vitamin D3 with $L$. paracasei DG appears particularly promising, considering the demonstrated probiotic properties of this bacterium, which include the ability to efficiently survive the gastrointestinal transit (Radicioni et al. 2019; Arioli et al. 2018), modulate the gut microbiota composition and butyrate levels in healthy adults (Ferrario et al. 2014) and irritable bowel syndrome (IBS) patients (Cremon et al. 2018), and regulate the immune response in vitro (Balzaretti et al. 2015; Balzaretti et al. 2017), ex vivo (Compare et al. 2017), and in vivo (D'Inca et al. 2011).

\section{Conclusion}

The results of this preliminary pre-clinical study suggest that the combined administration of $L$. paracasei DG cells with a conventional supplement of cholecalciferol may contribute to the maintenance of the adequate 25-hydroxyvitamin D serum levels in the population groups at risk of vitamin D deficiency. Further studies are warranted to assess synergistic effects of the combination between vitamin D and DG cells in terms of immune response, intestinal mucosal homeostasis, and microbiota composition and function, which can confer health benefits both at intestinal mucosal level and systemically.

\section{Methods}

\section{Bacterial strains and cultivation conditions}

Six bacterial strains belonging to the Lactobacillaceae family were investigated: Lacticaseibacillus paracasei (formerly Lactobacillus paracasei) CNCM I-1572 (L. casei DG ${ }^{\circledR}$; Enterolactis ${ }^{\circledR}$, SOFAR S.p.A.), Lacticaseibacillus paracasei DSM 26760 (strain LPC-S01), Lacticaseibacillus paracasei Shirota, Lacticaseibacillus rhamnosus (formerly Lactobacillus rhamnosus) ATCC 53103 (strain GG), Limosilactobacillus reuteri DSM 17938, and Lactobacillus acidophilus DSM13241 (strain LA5). All strains were cultivated in de Man Rogosa Sharpe (MRS; Difco) broth at $37^{\circ} \mathrm{C}$ overnight.

\section{In vitro evaluation of vitamin D3 emulsification by probiotic bacterial cells}

The cell pellet was recovered from the broth culture by centrifugation, washed twice with phosphate buffer saline solution (PBS; $\mathrm{pH}$ 7.3), and resuspended in PBS to an $\mathrm{OD}_{600 \mathrm{~nm}}=5$. Then, $100 \mu \mathrm{l}$ of DIBASE $(50.000 \mathrm{IU} / 2.5$ $\mathrm{ml}$ cholecalciferol in refined olive oil, Abiogen Pharma, Italy), corresponding to $2000 \mathrm{IU}(2.5 \mu \mathrm{g})$ of cholecalciferol was dispersed in $1 \mathrm{ml}$ of the bacterial suspension and incubated under magnetic stirring $(500 \mathrm{rpm})$ for $45 \mathrm{~min}$. Next, after mild centrifugation (2000 rpm, $2 \mathrm{~min}$ ), $400 \mu \mathrm{l}$ of the aqueous phase laying below the oil phase was taken by means of the needle of a sterile syringe. Subsequently, cholecalciferol was extracted from the aqueous samples using the following method: $400 \mu \mathrm{l}$ of methanol was added to the sample and the mixture was extracted once 
with two volumes of hexane. The hexane phase obtained after centrifugation (13000 rpm, $3 \mathrm{~min}$ ) was evaporated to dryness under nitrogen, and the dried residue was dissolved in $150 \mu \mathrm{l}$ of HPLC mobile phase. A volume of 100 $\mu \mathrm{l}$ was used for HPLC analysis.

\section{HPLC analysis}

Cholecalciferol was separated using a $4.6 \times 100 \mathrm{~mm}$, $2.7 \mu \mathrm{m}$ Poroshell 120 EC-C18 column in a HPLC system comprising an Agilent separation module (1260 infinity II pumps with autosampler), and 1260 infinity II variable wavelength detector (detection at $265 \mathrm{~nm}$ for vitamin D). The chromatographic protocol was according to Goncalves et al. (2011). In brief, the mobile phase was $60 \%$ acetonitrile, $38 \%$ methanol, and $2 \%$ water. Flow rate was 1 $\mathrm{ml} / \mathrm{min}$, and the column was kept at a constant temperature $\left(40^{\circ} \mathrm{C}\right)$. Cholecalciferol was identified by spectral analysis and/or retention time and co-injection compared with pure standard. Quantification was performed with open Lab HPLC agilent software comparing peak area with standard reference curve.

\section{Mice and treatments}

Male CD-1 mice (8 weeks old) were purchased from Charles River (Monza, Italy). Mice were housed in group of 4 per cage and maintained in a temperature-controlled environment $\left(22 \pm 2^{\circ} \mathrm{C}\right)$ under a 12-h-light/dark cycle with regular chow food and tap water provided ad libitum. Following a week of acclimation period, they were randomly assigned to one of six experimental groups (Fig. 2). Each animal received the specific treatment at 9 a.m. by intragastric gavage (24 gauge, 9 -cm catheter) in a total volume of $100 \mu \mathrm{l}$. Mice receiving vitamin D3 were gavaged with 10,000 IU of vitamin D3 in refined olive oil (DIBASE preparation) per kilogram of body weight either as a single dose or daily for a week. To this purpose, 25 $\mu \mathrm{l}$ aliquots, each containing $500 \mathrm{IU}$ of vitamin, were prepared in sterile conditions for supplementation to the animals, having an average body weight of $50 \mathrm{~g}$, and stored at room temperature. Mice receiving the probiotic cells were gavaged with $10^{8}$ CFUs of $L$. paracasei DG in a single administration per day for a week. To this purpose, bacterial broth culture was centrifuged, and the resulting cell pellet was washed twice with sterile saline solution and finally resuspended with the appropriate volume of an aqueous solution of sucrose $20 \%+$ glycerol $10 \%$ (w/ vol). The suspension was diluted to $\mathrm{OD}_{600 \mathrm{~nm}}=1$ and then partitioned into $150 \mu \mathrm{l}$ aliquots, which were immediately frozen at $-20^{\circ} \mathrm{C}$ until dry ice delivery at the Department of Molecular Medicine of the University of Padova. Each aliquot had a cell concentration of $1.6 \times 10^{9} \mathrm{CFU} / \mathrm{ml}$ (corresponding to $2.4 \times 10^{8} \mathrm{CFU} /$ aliquot) as calculated by agar plate count on MRS agar. When administered together (groups $\mathrm{V}$ and $\mathrm{VI}$ ), the aliquot of vitamin $\mathrm{D}$ and the bacterial cell suspension were mixed by manual shaking and pipetting immediately before gavage. Control mice (group I) received only the aqueous solution of sucrose $20 \%+$ glycerol $10 \%(\mathrm{w} / \mathrm{vol}$ ) for 1 week.

\section{Vitamin D quantification in mouse serum}

Three hours after the last treatment, mice were anesthetized with halothane and the blood was collected by cardiac puncture. Serum was separated from blood through centrifugation, collected, and immediately frozen until the dosage of the vitamin $\mathrm{D}$. The serum level vitamin $\mathrm{D}$ was quantified in the form of 25-hydroxyvitamin $\mathrm{D}$ $(25(\mathrm{OH}) \mathrm{D})$ by a competitive binding assay $(25 \mathrm{OH}$ vitamin D total ELISA, Gentaur, Bergamo, IT) optimized for mouse serum. Vitamin D3 bioavailability was tested through ELISA quantification of the $25(\mathrm{OH}) \mathrm{D}$ in mouse serum, because the blood level of this metabolite is conventionally considered a valid biomarker of the vitamin $\mathrm{D}$ status (Thienpont et al. 2012).

\section{Statistical analysis}

Data are reported as the mean \pm standard deviation. Data were analyzed with the Levene's test for assessing the equality of variances. Then, since the variance between groups resulted different, we performed the Welch's ANOVA test followed by an unpaired $t$ test with Welch's correction to find statistically significant differences between groups. Differences were considered significant at $P<0.05$.

\section{Acknowledgements \\ None.}

\section{Authors' contributions}

Conceptualization, I.C., P.B., M.E., and S.G.; investigation, G.B., M.E., and V.D.V.; data curation, S.G., M.S., V.D.V., and P.B.; writing —original draft preparation, V.S. and S.G.; writing - review and editing, W.F., S.G., M.E., and I.C. The authors have read and agreed to the published version of the manuscript.

\section{Funding}

This work was financially supported by Sofar S.p.A.

\section{Availability of data and materials}

The datasets used and/or analyzed during the current study are available from the corresponding author on reasonable request.

\section{Declarations}

Ethics approval and consent to participate

All experimental protocols were approved by the Animal Care and Use Ethics Committee of the University of Padova under license from the Italian Ministry of Health and complied with the national and European guidelines for handling and use of experimental animals and with the ARRIVE guidelines.

Consent for publication

Not applicable. 


\section{Competing interests}

Sofar S.p.A. is a private company that commercializes probiotic supplements containing L. paracasei DG. Walter Fiore and Valerio De Vitis are employees of Sofar S.p.A. Simone Guglielmetti is consultant of Sofar S.p.A. Other authors declare that they have no known competing financial interests or personal relationships that could have appeared to influence the work reported in this paper.

\begin{abstract}
Author details
${ }^{1}$ Department of Molecular Medicine, University of Padua, 35121 Padua, Italy. ${ }^{2}$ AAT-Advanced Analytical Technologies S.r.l., Fiorenzuola d'Arda, Piacenza, Italy. ${ }^{3}$ SOFAR S.p.A., Trezzano Rosa, Milan, Italy. ${ }^{4}$ Division of Food Microbiology and Bioprocesses, Department of Food, Environmental and Nutritional Sciences (DeFENS), University of Milan, 20133 Milan, Italy.
\end{abstract}

Received: 31 August 2021 Accepted: 6 October 2021 Published online: 18 October 2021

\section{References}

Arioli S, Koirala R, Taverniti V, Fiore W, Guglielmetti S $(2018,1720)$ Quantitative recovery of Viable Lactobacillus paracasei CNCM I-1572 (L. casei DG(R)) after gastrointestinal passage in healthy adults. Front Microbiol 9

Balzaretti S, Taverniti V, Guglielmetti S, Fiore W, Minuzzo M, Ngo HN et al. (2017) A novel rhamnose-rich hetero-exopolysaccharide isolated from Lactobacillus paracasei DG activates THP-1 Human monocytic cells. Applied and environmental microbiology 83.

Balzaretti S, Taverniti V, Rondini G, Marcolegio G, Minuzzo M, Remagni MC et al (2015) The vaginal isolate Lactobacillus paracasei LPC-S01 (DSM 26760) is suitable for oral administration. Front Microbiol 6:952

Bergman GJ, Fan T, McFetridge JT, Sen SS (2010) Efficacy of vitamin D3 supplementation in preventing fractures in elderly women: a meta-analysis. Curr Med Res Opinion 26:1193-1201

Bogovic Matijasic B, Obermajer T, Lipoglavsek L, Sernel T, Locatelli I, Kos M et al (2016) Effects of synbiotic fermented milk containing Lactobacillus acidophilus La-5 and Bifidobacterium animalis ssp. lactis BB-12 on the fecal microbiota of adults with irritable bowel syndrome: a randomized double-blind, placebo-controlled trial. J Dairy Sci 99:5008-5021

Borel P, Caillaud D, Cano NJ (2015) Vitamin D bioavailability: state of the art. Critical reviews in food science and nutrition 55:1193-1205

Boulkrane MS, Ilina V, Melchakov R, Fedotova J, Drago F, Gozzo L et al (2020) COVID-19 disease and vitamin D: a mini-review. Frontiers in pharmacology 11:604579

Calvo C, Martinez-Checa F, Toledo FL, Porcel J, Quesada E (2002) Characteristics of bioemulsifiers synthesised in crude oil media by Halomonas eurihalina and their effectiveness in the isolation of bacteria able to grow in the presence of hydrocarbons. Applied microbiology and biotechnology 60:347-351

Capurso L (2019) Thirty years of Lactobacillus rhamnosus GG: a review. J Clinical Gastroenterology 53(Suppl 1):S1-S41

Ciandrini E, Campana R, Casettari L, Perinelli DR, Fagioli L, Manti A et al (2016) Characterization of biosurfactants produced by Lactobacillus spp. and their activity against oral streptococci biofilm. Applied microbiology and biotechnology 100:6767-6777

Compare D, Rocco A, Coccoli P, Angrisani D, Sgamato C, lovine B et al (2017) Lactobacillus casei DG and its postbiotic reduce the inflammatory mucosal response: an ex-vivo organ culture model of post-infectious irritable bowel syndrome. BMC gastroenterology 17:53

Cremon C, Guglielmetti S, Gargari G, Taverniti V, Castellazzi AM, Valsecchi C et al (2018) Effect of Lactobacillus paracasei CNCM I-1572 on symptoms, gut microbiota, short chain fatty acids, and immune activation in patients with irritable bowel syndrome: a pilot randomized clinical trial. United European gastroenterology journal 6:604-613

Cross HS, Nittke T, Kallay E (2011) Colonic vitamin D metabolism: implications for the pathogenesis of inflammatory bowel disease and colorectal cancer. Molecular and cellular endocrinology 347:70-79

Cutolo M, Paolino S, Smith V (2020) Evidences for a protective role of vitamin D in COVID-19. RMD open 6

Dibaba DT (2019) Effect of vitamin D supplementation on serum lipid profiles: a systematic review and meta-analysis. Nutrition reviews 77:890-902
D'Inca R, Barollo M, Scarpa M, Grillo AR, Brun P, Vettorato MG et al (2011) Rectal administration of Lactobacillus casei DG modifies flora composition and Toll-like receptor expression in colonic mucosa of patients with mild ulcerative colitis. Digestive diseases and sciences 56:1178-1187

Dobson R, Cock HR, Brex P, Giovannoni G (2018) Vitamin D supplementation. Practical neurology 18:35-42

Ferrario C, Taverniti V, Milani C, Fiore W, Laureati M, De Noni l et al (2014) Modulation of fecal Clostridiales bacteria and butyrate by probiotic intervention with Lactobacillus paracasei DG varies among healthy adults. The Journal of nutrition 144:1787-1796

Ghaly S, Kaakoush NO, Lloyd F, McGonigle T, Mok D, Baird A et al (2018) High dose vitamin D supplementation alters faecal microbiome and predisposes mice to more severe colitis. Sci Rep 8:11511

Goncalves A, Gleize B, Bott R, Nowicki M, Amiot MJ, Lairon D et al (2011) Phytosterols can impair vitamin $D$ intestinal absorption in vitro and in mice. Mol Nutr Food Res 55(Suppl 2):S303-S311

Grant WB, Lahore H, MCDonnell SL, Baggerly CA, French CB, Aliano JL et al (2020) Evidence that vitamin D supplementation could reduce risk of influenza and COVID-19 infections and deaths. Nutrients 12

Gutierrez T, Berry D, Yang T, Mishamandani S, McKay L, Teske A et al (2013) Role of bacterial exopolysaccharides (EPS) in the fate of the oil released during the deepwater horizon oil spill. PloS one 8:e67717

Gutierrez T, Morris G, Green DH (2009) Yield and physicochemical properties of EPS from Halomonas sp. strain TG39 identifies a role for protein and anionic residues (sulfate and phosphate) in emulsification of $n$-hexadecane. Biotechnology and bioengineering 103:207-216

Halfon M, Phan O, Teta D (2015) Vitamin D: a review on its effects on muscle strength, the risk of fall, and frailty. BioMed research international 2015:953241

Hattangdi-Haridas SR, Lanham-New SA, Wong WHS, Ho MHK, Darling AL (2019) Vitamin D deficiency and effects of vitamin D supplementation on disease severity in patients with atopic dermatitis: a systematic review and meta-analysis in adults and children. Nutrients 11

Holick MF (2007) Vitamin D deficiency. The New England J Med 357:266-281

Holick MF (2017) The vitamin D deficiency pandemic: approaches for diagnosis, treatment and prevention. Rev Endocrine Metabolic Dis 18:153-165

Holick MF, Schnoes HK, DeLuca HF (1971) Identification of 1,25-dihydroxycholecalciferol, a form of vitamin D3 metabolically active in the intestine. Proceedings of the National Academy of Sciences of the United States of America 68:803-804

Hollander D, Muralidhara KS, Zimmerman A (1978) Vitamin D-3 intestinal absorption in vivo: influence of fatty acids, bile salts, and perfusate $\mathrm{pH}$ on absorption. Gut 19:267-272

Hollis BW (1996) Assessment of vitamin D nutritional and hormonal status: what to measure and how to do it. Calcified tissue international 58:4-5

Jager R, Zaragoza J, Purpura M, lametti S, Marengo M, Tinsley GM et al (2020) Probiotic administration increases amino acid absorption from plant protein: a placebo-controlled, randomized, double-blind, multicenter, crossover study. Probiotics Antimicrob Proteins 12:1330-1339

Jahan R, Bodratti AM, Tsianou M, Alexandridis P (2020) Biosurfactants, natural alternatives to synthetic surfactants: physicochemical properties and applications. Advances in colloid and interface science 275:102061

Jones ML, Martoni CJ, Prakash S (2013) Oral supplementation with probiotic L. reuteri NCIMB 30242 increases mean circulating 25-hydroxyvitamin D: a post hoc analysis of a randomized controlled trial. The J Clin Endocrinology Metab 98:2944-2951

Koirala R, Gargari G, Arioli S, Taverniti V, Fiore W, Grossi E et al (2020) Effect of oral consumption of capsules containing Lactobacillus paracasei LPCS01 on the vaginal microbiota of healthy adult women: a randomized, placebo-controlled, double-blind crossover study. FEMS microbiology ecology 96

Leclair TR, Zakai N, Bunn JY, Gianni M, Heyland DK, Ardren SS et al (2019) Vitamin D supplementation in mechanically ventilated patients in the medical intensive care unit. JPEN Journal of parenteral and enteral nutrition 43:1037-1043

Mallya SM, Corrado KR, Saria EA, Yuan FF, Tran HQ, Saucier K et al (2016) Modeling vitamin D insufficiency and moderate deficiency in adult mice via dietary cholecalciferol restriction. Endocrine research 41:290-299

Marwaha RK, Dabas A (2019) Bioavailability of nanoemulsion formulations vs conventional fat soluble preparations of cholecalciferol (D3) - an overview. Journal of clinical orthopaedics and trauma 10:1094-1096 
Maurya VK, Aggarwal M (2017) Factors influencing the absorption of vitamin D in GIT: an overview. Journal of food science and technology 54:3753-3765

Milajerdi A, Ostadmohammadi V, Amirjani S, Kolahdooz F, Asemi Z (2019) The effects of vitamin D treatment on glycemic control, serum lipid profiles, and C-reactive protein in patients with chronic kidney disease: a systematic review and meta-analysis of randomized controlled trials. International urology and nephrology 51:1567-1580

Mobini R, Tremaroli V, Stahlman M, Karlsson F, Levin M, Ljungberg M et al (2017) Metabolic effects of Lactobacillus reuteri DSM 17938 in people with type 2 diabetes: a randomized controlled trial. Diabetes, obesity \& metabolism 19:579-589

Morovic W, Hibberd AA, Zabel B, Barrangou R, Stahl B (2016) Genotyping by $P C R$ and high-throughput sequencing of commercial probiotic products reveals composition biases. Frontiers in microbiology 7:1747

Nanno M, Kato I, Kobayashi T, Shida K (2011) Biological effects of probiotics: what impact does Lactobacillus casei shirota have on us? International journal of immunopathology and pharmacology 24:45S-50S

Nasirpour H, Azari Key Y, Kazemipur N, Shadman B, Hajazimian S, isazadeh a et al. (2019) The effects of cholesterol lowering drugs on vitamin D status in familial hypercholesterolemia patients. Archives of Medical Laboratory Sciences 3.

Norman AW, Myrtle JF, Midgett RJ, Nowicki HG, Williams V, Popjak G (1971) 1,25-dihydroxycholecalciferol: identification of the proposed active form of vitamin D3 in the intestine. Science 173:51-54

Palacios C, Trak-Fellermeier MA, Martinez RX, Lopez-Perez L, Lips P, Salisi JA et al (2019) Regimens of vitamin D supplementation for women during pregnancy. The Cochrane database of systematic reviews 10:CD013446

Papadimitriou DT (2017) The Big Vitamin D Mistake. Journal of preventive medicine and public health =. Yebang Uihakhoe chi 50:278-281

Patro-Golab B, Szajewska H (2019) Systematic review with meta-analysis: Lactobacillus reuteri DSM 17938 for treating acute gastroenteritis in children. An Update. Nutrients 11

Radicioni M, Koirala R, Fiore W, Leuratti C, Guglielmetti S, Arioli S (2019) Survival of L. casei DG((R)) (Lactobacillus paracasei CNCMI1572) in the gastrointestinal tract of a healthy paediatric population. European journal of nutrition 58:3161-3170

Santos DK, Rufino RD, Luna JM, Santos VA, Sarubbo LA (2016) Biosurfactants: multifunctional biomolecules of the 21st century. International journal of molecular sciences 17:401
Satpute SK, Kulkarni GR, Banpurkar AG, Banat IM, Mone NS, Patil RH et al (2016) Biosurfactant/s from Lactobacilli species: properties, challenges and potential biomedical applications. Journal of basic microbiology 56:1140-1158

Shang M, Sun J (2017) Vitamin D/VDR, probiotics, and gastrointestinal diseases. Current medicinal chemistry 24:876-887

Smith TJ, Lanham-New SA, Hart KH (2017) Vitamin D in adolescents: are current recommendations enough? The Journal of steroid biochemistry and molecular biology 173:265-272

Thienpont LM, Stepman HC, Vesper HW (2012) Standardization of measurements of 25-hydroxyvitamin D3 and D2. Scandinavian journal of clinical and laboratory investigation Supplementum 243:41-49

Tso P, Fujimoto K (1991) The absorption and transport of lipids by the small intestine. Brain research bulletin 27:477-482

Umar M, Sastry KS, Chouchane AI (2018) Role of vitamin d beyond the skeletal function: a review of the molecular and clinical studies. International journal of molecular sciences 19.

Weiss ST, Litonjua AA (2015) Vitamin D, the gut microbiome, and the hygiene hypothesis. How does asthma begin? American journal of respiratory and critical care medicine 191:492-493

Wimalawansa SJ (2012) Vitamin D in the new millennium. Current osteoporosis reports 10:4-15

Yang CY, Leung PS, Adamopoulos IE, Gershwin ME (2013) The implication of vitamin D and autoimmunity: a comprehensive review. Clinical reviews in allergy \& immunology 45:217-226

Zarrati M, Shidfar F, Nourijelyani K, Mofid V, Hossein zadeh-Attar MJ, Bidad K et al. (2013) Lactobacillus acidophilus La5, Bifidobacterium BB12, and Lactobacillus casei DN001 modulate gene expression of subset specific transcription factors and cytokines in peripheral blood mononuclear cells of obese and overweight people. BioFactors 39:633-643.

Zisi D, Challa A, Makis A (2019) The association between vitamin D status and infectious diseases of the respiratory system in infancy and childhood. Hormones 18:353-363

\section{Publisher's Note}

Springer Nature remains neutral with regard to jurisdictional claims in published maps and institutional affiliations.
Ready to submit your research? Choose BMC and benefit from:

- fast, convenient online submission

- thorough peer review by experienced researchers in your field

- rapid publication on acceptance

- support for research data, including large and complex data types

- gold Open Access which fosters wider collaboration and increased citations

- maximum visibility for your research: over 100M website views per year

At BMC, research is always in progress.

Learn more biomedcentral.com/submissions 